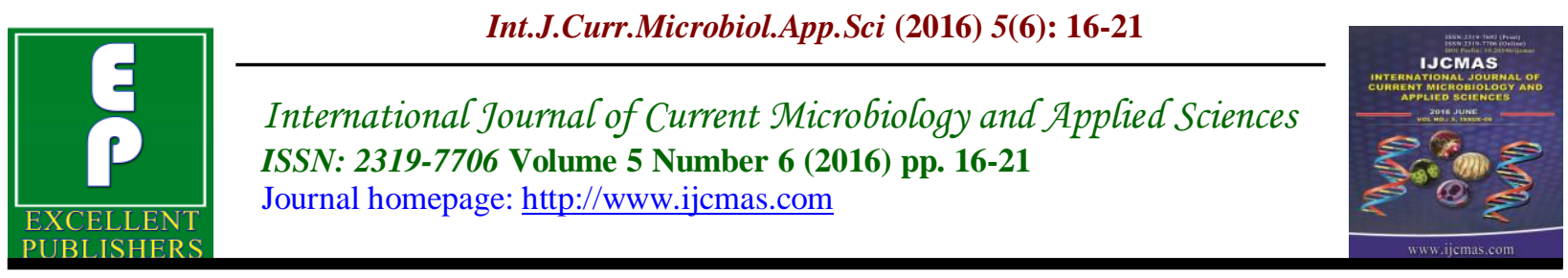

Original Research Article

http://dx.doi.org/10.20546/ijcmas.2016.506.002

\title{
Prevalence of Helicobacter pylori and its associated Peptic Ulcer Infection among Adult Residents of Aba, Southeastern, Nigeria
}

\author{
Ezeigbo, R. Obiageli ${ }^{1 *}$ and Ezeigbo C. Ivan ${ }^{2}$ \\ ${ }^{1}$ Department of Biology/Microbiology, Abia State Polytechnic, Aba, Nigeria \\ ${ }^{2}$ Natural and Computational Sciences, Minerva Schools at KGI, San Francisco, California, USA \\ *Corresponding author
}

Keywords

Helicobacter

pylori,

peptic ulcer,

Gram-negative

bacterium.

\section{Article Info}

Accepted:

07 May 2016

Available Online:

10 June 2016

\section{A B S T R A C T}

Helicobacter pylori (H. pylori) formerly known as Campylobacter pylori is a spiral rod-shaped Gram-negative, microaerophilic bacterium found in the stomach of infected person(s) causing duodenal ulcer, gastric ulcer and gastric cancer. Faecal and blood samples were collected from adult residents of Aba, Southeastern Nigeria between the months of March and July, 2015 for analysis using Diaspot $H$. pylori test kit and Faecal occult blood test. Out of three hundred (300) sampled, consisting of 128(42.7\%) males and $172(57.3 \%)$ females, a total of 119(39.7\%) were infected with Helicobacter pylori while 129(43.0\%) had peptic ulcer. A slightly higher percentage with peptic ulcer suggests that some other causes may have contributed to the peptic ulcer infection. However, the association of $H$. pylori with peptic ulcer positivity was found to be statistically non-significant ( $p$-value > 0.05). The highest prevalence for $H$. pylori infection and peptic ulcer occurred within the age group 38-47 years with $56.2 \%$ and $49.3 \%$ respectively, while ages 18-27 years had the least prevalence for both infections. The sex-related prevalence of $H$. pylori showed that more males were infected than females and both infections increased with age. However, prevalence of $H$. pylori infection and peptic ulcer are not significantly associated with sex and age of the patients ( $p$-value $>0.05$ ). This study confirms Helicobacter pylori as a contributor and causative agent of peptic ulcer and recommends maximum food hygiene practice and clean environment by food handlers.

\section{Introduction}

Helicobacter pylori (H. pylori) is a spiralshaped Gram-negative microaerophilic bacterium that grows in human gastric epithelial tissues and mucus of the stomach (Brooks et al., 2004; Chey et al., 2007). H. pylori remains one of the most common worldwide human infections and is associated with a number of important chronic gastritis, peptic ulcer disease, and gastric malignancy (Shamsuddeen et al., 2009). The prevalence of $H$. pylori is closely associated with socioeconomic conditions and accordingly, this infection is more common in developing countries than in developed countries (Everhart, 2000). About $40 \%$ of persons over 60 years of age have Helicobacter pylori (Gastroenterological society of Australia, 2003 on Facts about 
Helicobacter pylori). Most people are infected in childhood. Helicobacter pylori causes more than $90 \%$ of duodenal ulcers and up to $80 \%$ of gastric ulcers. Approximately two-thirds of the world's population is infected with $H$. pylori. In the United State, $H$. pylori is more prevalent among older adults, African American, Hispanics and lower socioeconomic groups. Although, the prevalence of $H$. pylori infection in developed countries seems to be decreasing, it is still high in developing world with as much as 90\% (Konturek, 2008). In developing countries, $70-90 \%$ of the population carries $H$. pylori; almost all of these acquired the infection before the age of 10 years (Taylor and Parsonnet, 1995). In developed countries, the prevalence of infection is lower, ranging from $25-50 \%$. The data from developed countries also suggests that most infections are acquired in childhood (Taylor and Parsonnet, 1995). These remarkable organisms survive the extreme acidity of the stomach because of its ability to split urease to release nitrogen which increases the $\mathrm{pH}$ of gastric acid and for protein synthesis; thus creating an alkaline microenvironment by hydrolyzing urea to ammonia. Other intestinal parasites like hookworms Ascaris lumbricoides, roundworms and non-steroid anti-inflammatory drugs (NSAIDS) such as Aspirin and Ibuprofen also contribute to the development of ulcer (Parkin et al., 1999). Symptoms include abdominal discomfort, weight loss, bloating, burping, nausea/vomiting and release of bloody or dark coloured stool, bloody vomit or coffee vomits and bleeding.

The treatment of $H$. pylori remains a challenging clinical problem despite extensive research over the last 25 years (Egan et al., 2007). Bacterial resistance and poor patient compliance are believed to be the primary factors in $H$. pylori treatment failure (Megraud, 2004). The occurrence of side-effects has reduced the compliance of patients with treatment regimens and led to the development of bacterial resistance (de Bortoli et al., 2007). This has led to the development of alternative treatment options in $H$. pylori. Increasing antimicrobial resistance and falling eradication rates are the result of the widespread use of antibiotics (Egan et al., 2007). The prevalence of antimicrobial resistance in $H$. pylori shows regional variation both within and between countries. However, alternative antibiotics based on local resistance rates may improve eradication rates (Egan et al., 2007). This survey is aimed at determining the prevalence of $H$. pylori and its associated peptic ulcer infection in Aba, Southeastern Nigeria.

\section{Materials and Methods}

\section{Study Area}

Aba is a major settlement and commercial center in the southeastern part of Nigeria. The geographical co-ordinates for Aba are $5^{\circ} 07 \mathrm{~N}$ latitude and $7^{\circ} 22 \mathrm{E}$ longitude and 205m (673ft) above sea level. Aba consists of two Local Government Areas: Aba North and Aba South LGAs. The city is thickly populated with small towns and villages. The people are predominantly traders, artisans, farmers and public/civil servants. Because of climatic nature of the studied area (Aba being in the rainforest zone), compounded with the socioeconomic nature of the people, infections associated with personal and environmental hygiene are common.

\section{Research Ethics}

Ethical review and clearance of the research protocol were obtained from the Ethical Review Committee of the Department of 
Biology/Microbiology, Abia State Polytechnic, Aba. Permission was sought from each of the Local Government Chairmen. All subjects who gave their consent and are willingness to participate in this study signed the consent form and presented their identification data (name, age, sex, occupation etc).

\section{Sample Collection}

Blood and stool samples were randomly collected from 300 adult individuals between the ages of 18 years and above. About $2 \mathrm{~mL}$ of venous blood was collected from each subject into an EDTA bottle (labeled with code numbers, age and sex) using $5 \mathrm{~mL}$ syringe. Stool samples were also collected with the use of catching device (hat-shaped plastic lid). The catching device prevents contamination of the stool samples by water, urine or dirt. The stool samples were put in sterile screw-capped bottles and labeled with identification numbers. The collected samples were taken to the Microbiology Laboratory of Abia State Polytechnic, Aba for analysis.

\section{Analysis of the Samples}

The presence of $H$. pylori was determined by Blood Antibody Test and Stool Antigen Test.

Blood Antibody test was carried out using H. pylori Test device (Diaspot H. pylori), an invitro chromatographic immunoassay for the qualitative detection of $H$. pylori antibodies. Each of the $2 \mathrm{~mL}$ of blood samples collected was centrifuged for 20 minutes. The blood formed two layers (the serum and the red blood cells). The Diaspot $H$. pylori test kits were placed on a clean table. A rubber dropper was used to transfer 3 drops of serum into each well of the test kit and timed for 20 minutes to observe for the presence or absence of one or two coloured lines: one is the control region (C) while the other is the test region (T). The appearance of one coloured line on the control region indicates a negative result while the appearance of two coloured lines both on the test region and control region indicates positive result to $H$. pylori infection.

Faecal occult blood test was performed in the laboratory by thoroughly emulsifying $2 \mathrm{~g}$ of each stool sample in $5 \mathrm{~mL}$ of normal saline in a test tube (faecal occult blood test tube), using sterile rod, and each placed in a test tube rack. The emulsified stool samples were allowed to sediment, after which, a faecal occult test strip was dropped into the mixture and allowed to absorb it. Two red lines at the middle of the strip indicate a positive result, while negative result is an indication of one red line.

\section{Statistical Analysis}

Statistical analysis was done using statistical package for social sciences (SPSS) version 20.0. Statistical significance tests included the use of $p$-value to assess the role of chance and $\chi^{2}$ (Chisquare) test to account for the association between different variables. In this study, $p$-value $<0.05$ was used to disapprove the null hypothesis.

\section{Results and Discussion}

Table 1 represents the sex-related prevalence of $H$. pylori and peptic ulcer. Out of 300 adult individuals examined, consisting of $128(42.7 \%)$ males and $172(57.3 \%)$ females, $119(39.7 \%)$ were infected with $H$. pylori compared to129 (43.0\%) with peptic ulcer. The prevalence of H. pylori infection and peptic ulcer are not significantly associated with sex $(\mathrm{P}=0.242$, $\mathrm{t}=-2.500)$. 
Table.1 Sex-related Prevalence of H. pylori infection and Peptic ulcer

\begin{tabular}{llll}
\hline Sex & $\begin{array}{l}\text { Number } \\
\text { Examined }(\%)\end{array}$ & $\begin{array}{l}\text { Number Positive } \\
\text { for } H . \text { pylori }(\%)\end{array}$ & $\begin{array}{l}\text { Number Postic ulcer }(\%) \\
\text { peptive for }\end{array}$ \\
\hline Male & $128(42.7)$ & $51(39.8)$ & $54(42.2)$ \\
Female & $172(57.3)$ & $68(39.5)$ & $75(43.6)$ \\
Total & 300 & $119(39.7)$ & $129(43.0)$ \\
\hline
\end{tabular}

Table.2 Age-related Prevalence of H. pylori infection and Peptic ulcer

\begin{tabular}{llll}
\hline Age (years) & $\begin{array}{l}\text { Number } \\
\text { Examined } \\
(\%)\end{array}$ & $\begin{array}{l}\text { Number positive } \\
\text { for H.pylori }(\%)\end{array}$ & $\begin{array}{l}\text { Number } \\
\text { Positive for } \\
\text { peptic ulcer }\end{array}$ \\
\hline $18-27$ & $135(45.0)$ & $45(33.3)$ & $50(37.0)$ \\
$28-37$ & $92(30.7)$ & $33(35.9)$ & $43(46.7)$ \\
$38-47$ & $73(24.3)$ & $41(56.2)$ & $36(49.3)$ \\
Total & 300 & $119(39.7)$ & $129(43.0)$ \\
\hline
\end{tabular}

H. pylori and peptic ulcer infections are statistically not significant $(\mathrm{P}=0.529, \mathrm{t}=$ $0.756)$.

The age-related prevalence of $H$. pylori and peptic ulcer is shown in Table 2. The highest prevalence for both $H$. pylori and peptic ulcer occurred within the age group 38-47 years with $56.2 \%$ and $49.3 \%$ respectively, while ages 18-27 years had the least for both the bacterial infection and peptic ulcer. Agedistribution of $H$. pylori and peptic ulcer infection is not statistically significant $(\mathrm{P}=0.568, \mathrm{t}=0.386)$.

H. pylori are spiral-shaped bacteria that can cause peptic ulcer disease by damaging the mucous coating that protects the lining of the stomach and duodenum. This study investigated the prevalence of $H$. pylori infection and peptic ulcer in Aba,
Southeastern Nigeria. The result showed that the $H$. pylori infection is endemic in the studied area. On the relationship between $H$. pylori and peptic ulcer, result showed nonsignificant difference in their prevalence. This therefore confirmed the link between $H$. pylori and the pathogenesis of peptic ulcer disease (Paptheodoridis et al., 2006; Chey et al., 2006). Although, H. pylori is known to cause peptic ulcer, others like nonsteroidal anti-inflammatory drugs have also been implicated by other authors (Peterson, 1991; Parkin et al., 1999). On sex-related prevalence of $H$. pylori and peptic ulcer, the result revealed that males and females are approximately infected although more males were infected than females. The statistical analysis showed there is no significant difference in prevalence between the males and the females and this agrees with the findings of other authors (Tarkhashvili et al., 
2009; Shokrzadeh et al., 2012; Adlekha et al., 2013). On age -related prevalence, the results also revealed that both $H$. pylori infection and peptic ulcer increased with age; however this is not significantly different. This result agrees with the findings of Tarkhashvili et al (2009) and Adlekha et al (2013) but contrasts with the results of Shokrzadeth et al (2012) and Kaore et al (2012) were H. pylori positivity increased with age of 20-40 years. There is a need therefore to create awareness on $H$. pylori infection and its associated peptic ulcer infection in Aba.

In conclusion, this study evaluated the prevalence of Helicobacter pylori $(H$. pylori), a Gram-negative bacterium that causes peptic ulcer. The close association between the two infections suggests that $H$. pylori could be a major cause of peptic ulcer; although other causes such as nonsteroidal anti-inflammatory drugs and Aspirin (taken to prevent heart attack or stroke) have also been implicated. Personal hygiene and early detection and treatment of $H$. pylori will go a long way in eradicating the infection and its associated peptic ulcer infection.

\section{Acknowledgement}

The authors wish to acknowledge the approval of the Aba North and South local government authorities in the collection of samples.

\section{References}

Adlekha, S., Chadha, T., Krishnan, P., Sumangala, B. 2013. Prevalence of Helicobacter pylori infection among patients undergoing upper gastrointestinal endoscopy in a medical college hospital in Kerala, India. Annals of Med. Health Sci. Res.,
3(4): 559-563.

Brooks, G.F., Butel, J.S., Morse, S.A. 2004. Jawetz, Melnick, and Adelberg's Medical Microbiology, 23rd edition, Mc Graw Hill International Edition, New York. Pp 275- 6.

Chey, W.D., Wong, B.C.Y., Practice Parameters Committee of the American College of Gastroenterology Guideline on the management of Helicobacter pylori infection. J. Gastroenterol., 102: 1808-1825.

De Bortoli, N., Leonardi, G., Ciancia, E., Merio, .A, Bellini, M., Costa, F., Mumolo, M.G., Ricchiuti, A., Cristiani, F., Santi, .S, Rossi, M., Marchi, S. 2007. Helicobacter pylori eradication: a randomized prospective study of triple therapy versus triple therapy plus lactoferron and probiotics. Am. J. Gastroenterol., 102(5): 951-956.

Egan, B.J., Katicic, M., O’Connor, H.J., O'Morain, C.A. 2000. Treatment of Helicobacter pylori. Helicobacter, 12(suppl. 1):13-37.

Everhart, J.E. 2000. Recent development in the epidemiology of Helicobacter pylori. Gastroenterol. Clin. N. Am., 29: 559-578.

Kaore, N.M,. Nagdeo, N.V., Thombare, V.R. 2012. Comparative evaluation of the diagnostic tests for Helicobacter pylori and dietary influence for its acquisition in dyspeptic patients: A rural hospital based study in central India. JCDR, 6: 636-641.

Konturek, J.W. 2008. Helicobacter pylori and its pathogenicity role in peptic ulcer, gastritis and gastric cancer. $J$. Physio-pharmacol., 54(suppl. 3): 2341.

Megraud, F. 2004. Helicobacter pylori antibiotics resistance: prevalence, important and advances in testing. 
Gut, 53: 1374-1384.

Paptheodoridis, G.V., Sougioultzis, S., Archimandritis, A.J. 2006. Effect of Helicobacter pylori and nonsteroidal anti-inflammatory drugs on peptic ulcer disease: A systematic review. Clin. Gastroenterol Hepatol., 4: 130142.

Parkin, D.M., Pisani, P., Ferlay, J. 1999. Global cancer statistics. CA Cancer $J$. Clin., 49: 33-64.

Peterson, W.L. 1991. Helicobacter pylori and peptic ulcer disease. N. Engl. J. Med., 324: 1043-1048.

Shamsuddeen, U., Yusha'u, M., Adamu, I.A. 2009. Helicobacter pylori: the causative agent of peptic ulcer. Bayero J. Pure and Appl. Sci., 2(2): 79-83.

Shokrzadeh, L., Baghaei, K,. Yamaoka, Y., Shiota, S., Mirsattari, D, .Porhoseingholi, A., Zali, M.R. 2012. Prevalence of helicobacter pylori infection in dyspeptic patientsin Iran. Gastroenterol. insights, 4: 24-27.

Tarkhashvili, N., Beriashvili, R., Chakvetadze, N., Moistsrapishhvili, M., Chokheli, M., Sikharulidze, M., Malania, L., Abazashvil, N., Jhorjholiana, E., Chubinidze, M., Ninashvili, N., Zardiashvili, T., Gabunia, U., Kordzaia, D., Imnadze, P., Sobel, J., Guarner, J. 2009. Helicobacter pylori infection in patients undergoing upper endoscopy, Republic of Georgia. Emerg. Infect. Dis., 15: 504-505.

Taylor, D.N., Parsonnet, J. 1995. Epidemiological and natural history of Helicobacter pylori infections. In M. J. Blaser, P. F. Smith, J Ravdin, H. Greenberg and RL Guerrant (ed). Infections of the gastrointestinal tract. Raven Press, New York, pp 551-566.

\section{How to cite this article:}

Ezeigbo, R. Obiagelim and Ezeigbo C. Ivan. 2016. Prevalence of Helicobacter Pylori and its Associated Peptic Ulcer Infection among Adult Residents of Aba, Southeastern, Nigeria. Int.J.Curr.Microbiol.App.Sci. 5(6): 16-21. doi: http://dx.doi.org/10.20546/ijcmas.2016.506.002 